\title{
RISCOS GEOLÓGICOS ASSOCIADOS AOS MOVIMENTOS DE MASSA NAS FALÉSIAS DA COSTA DO DESCOBRIMENTO, BAHIA
}

\author{
$\underline{\text { Sasha Kaline Santana Botelho }}{ }^{1}$; Carlos César Uchôa de Lima ${ }^{2}$. \\ 1. Bolsista PROBIC/UEFS, Graduando em Engenharia Civil, Universidade Estadual de Feira de Santana, e-mail: \\ sashaksbotelho@gmail.com \\ 2. Orientador, Departamento de Ciências Exatas - DEXA, Universidade Estadual de Feira de Santana, e-mail: \\ uchoamaster@gmail.com
}

PALAVRAS-CHAVE: Movimentos de massa; juntas tectônicas; riscos geológicos.

\section{1 - INTRODUÇÃO}

Movimentos de massa ou fluxos gravitacionais de sedimentos, regolito e rochas, têm sido estudados tanto para as áreas urbanas, como para as margens de diversas rodovias. Esses estudos baseiam-se na premissa de que os movimentos de massa se constituem nos principais riscos geológicos de cidades topograficamente acidentadas, bem como, podem provocar acidentes e interrupções no tráfego ao longo de rodovias.

Embora movimentos de massa sejam muito estudados em áreas urbanas e ao longo de rodovias, poucos são os estudos associados a falésias (Santos Jr. et al., 2005). Entende-se por falésias, paredões rochosos de faces abruptas, formadas pela ação erosiva das ondas sobre as rochas (Suguio, 1998) e, por isso, podem estar sujeitas a constantes processos como erosão que geram a ocorrência de deslizamentos e por consequência o recuo das encostas. Na Costa do Descobrimento, encontram-se falésias podem atingir até $40 \mathrm{~m}$ de altura e são em parte caracterizadas como falésias ativas, onde suas bases estão constantemente expostas à ação das ondas e também aos processos erosivos provocados pela alta pluviosidade do sul do Estado da Bahia.

Os sedimentos que compõem as falésias da Costa do Descobrimento são pertencentes a Formação Barreiras, que data do Neógeno (Lima et al., 2006; Lima e Dominguez, 2015). Lima et al. (2006) fizeram uma descrição das litofácies presentes na mesma, identificando o predomínio de arenitos, folhelhos e siltitos e, secundariamente, aparecendo os conglomerados. Como estruturas geológicas mais abundantes, encontram-se as juntas tectônicas em pares conjugados de direções NW-SE e NE-SW (Lima et al., 2006).

Apesar de abrigar as cidades de Santa Cruz de Cabrália, Porto Seguro e Prado, a Costa do Descobrimento possui dezenas de quilômetros sem áreas urbanas, ocupada principalmente por empreendimentos de hotelaria e onde o fluxo turístico leva uma grande quantidade de visitantes, que têm nas praias as principais áreas de lazer. Este trabalho visa identificar os movimentos de massa que ocorrem nas falésias da Formação Barreiras, entre as localidades de Arraial D'Ajuda e Caraíva, Costa do Descobrimento, sul da Bahia, analisando de forma semiquantitativa, os riscos geológicos associados à instabilidade das falésias e aos movimentos de massa associados.

\section{2 - MÉTODOS}

Para que os objetivos traçados fossem alcançados, foi realizado um levantamento bibliográfico detalhado. Do mesmo modo, foi indispensável o reconhecimento da área através de idas ao campo, onde foi realizado o estudo de áreas nas quais existem registros de movimentos de massa e uma descrição das falésias.

Durante todo o trabalho de campo foram utilizados para realizar as medições, um GPS, uma bússola geológica de Brunton e uma câmera fotográfica.

A fim de realizar, da mesma maneira, a aplicação de técnicas de análise de risco, foi utilizada a metodologia proposta por Brissos et al. (2014) para a determinação do índice preliminar de risco de instabilidade de falésias, que possibilita indicação do índice de risco (IR) através de uma categorização numérica de termos como Perigosidade (P) e Vulnerabilidade (V) (Brissos et al., 2014), com a aplicação da seguinte equação: 
Índice de Risco $(I R)=\frac{\text { Probabilidade de ocorrência }(P O) \times \text { Magnitude }(M) x \text { Dano potencial }(D)}{\text { Capacidade de Resposta }(C)}$

Onde a Perigosidade é definida por $(\mathrm{PO} \times \mathrm{M})$ e a Vulnerabilidade por $(\mathrm{D} / \mathrm{C})$. Importante salientar que cada termo da equação foi categorizado de acordo com a significância: não significativa, reduzida, média, elevada e muito elevada, numa escala variando de 1 a 5 respectivamente. Os resultados podem variar de 0,2 a 125 e são recalculados para valores que estejam entre 0 e 1 , considerando assim, dentro desse intervalo, os valores de risco correspondentes ao perigo analisado. (Brissos et al., 2014, Fernandes et al., 2016)

Para categorizar a probabilidade de ocorrência (PO) e magnitude (M) foram observadas características como litologia e estrutura, identificação de blocos deslocados na base das falésias, ocorrência de percolação de água, bem como grau de fraturas e identificação de figuras instáveis. Já para o dano potencial, avaliamos quesitos relacionados a pessoas e bens no alto ou na base das falésias, bem como a presença de infraestruturas, o estado e tipo de acessibilidade às áreas estudadas. Finalmente, para o parâmetro da capacidade de resposta observamos quesitos acerca das características da vegetação, e outros quando presentes como visibilidade da sinalização, sistemas de contenção e perímetros de segurança (Fernandes et al., 2016).

\section{3 - RESULTADOS E DISCUSSÃO}

Dois domínios faciológicos foram identificados nos trabalhos de campo. O domínio 1 ocorre na porção basal das falésias e é dominado por arenitos maciços compactados mal selecionados, variando de areia fina a muito grossa, com grânulos e pequenos seixos imersos, composto principalmente de quartzo e feldspato. O domínio 2 é constituído por uma intercalação de camadas arenosas e argilosas de cores variadas, bastante friáveis. As areias variam de mal a moderadamente selecionadas, podendo apresentar estratificação cruzada. A partir da observação de inúmeros afloramentos ao longo da linha de costa estudada pudemos constatar a ocorrência de maneira predominante de dois tipos de movimentos de massa:
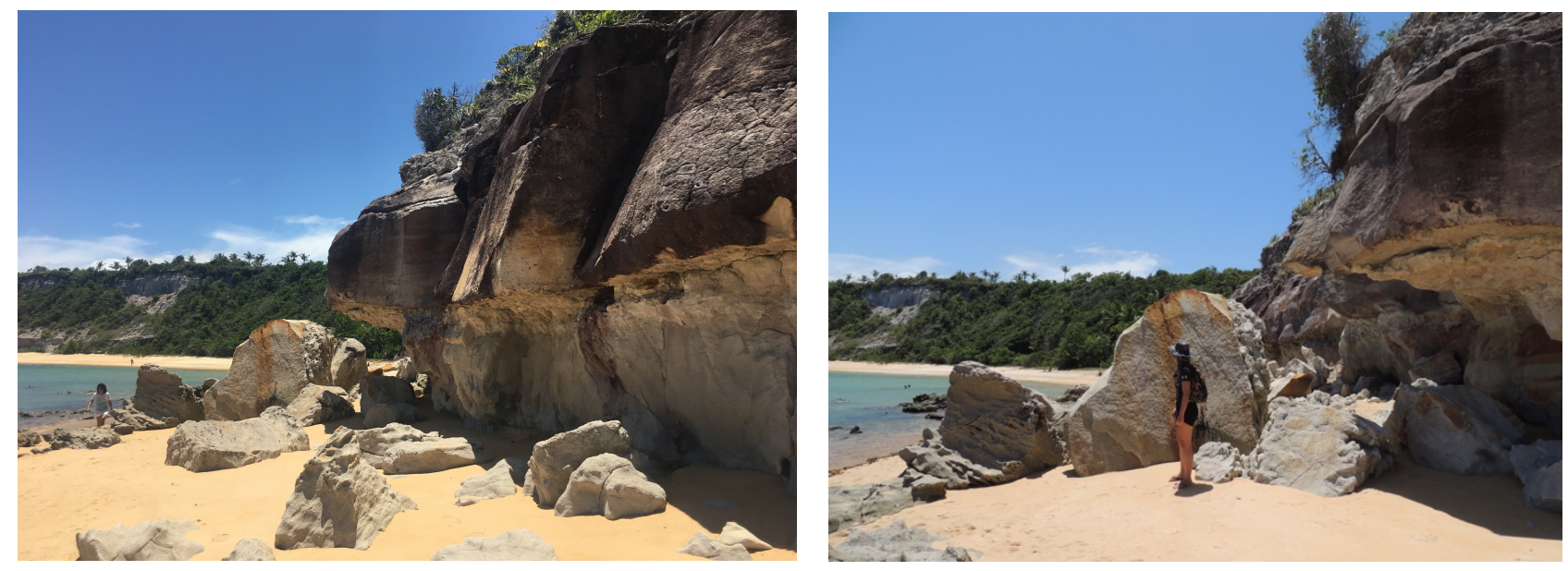

Figura 1 (a/b): Vários blocos de arenitos quartzo-feldspáticos, caídos próximos as falésias estudadas. São observadas juntas tectônicas, que se constituem em fragilidades ao longo das quais os blocos se desprendem e caem. 

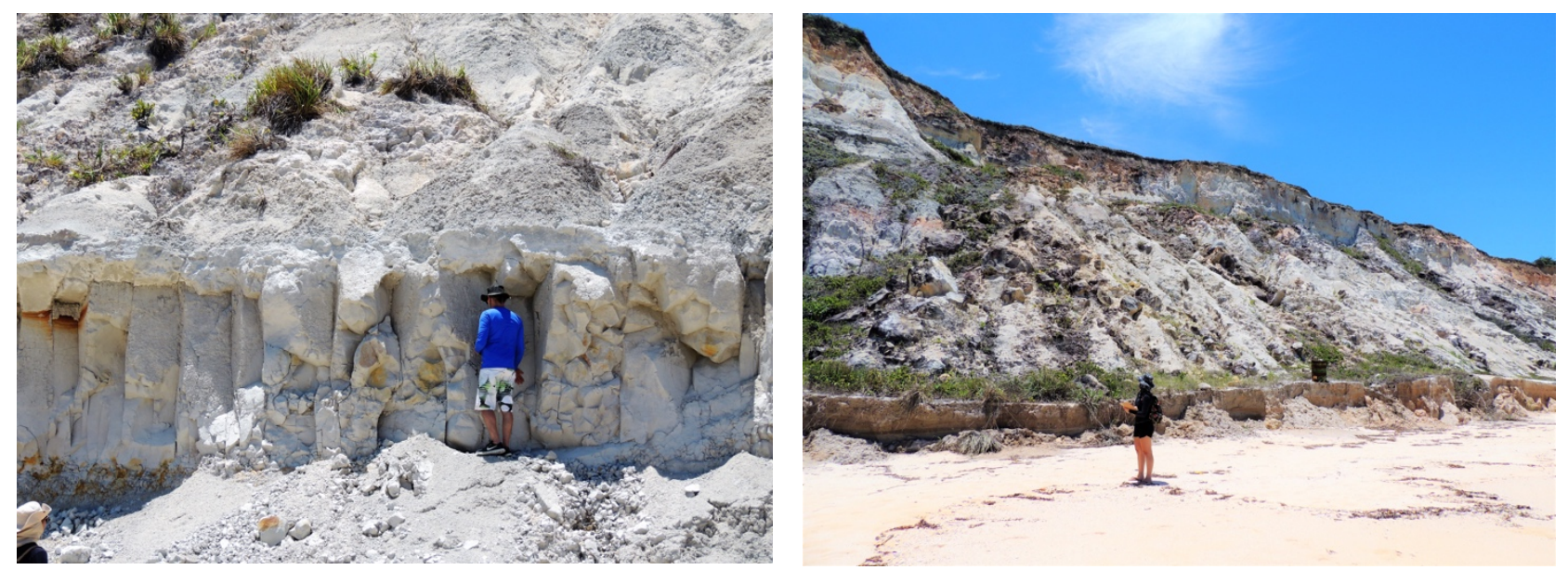

Figura 2a: Falésia da área estudada na qual se pode verificar os planos de fratura bem definidos ao longo da linha da própria falésia, se apresentando como pontos de fragilidade que influem para a ocorrência dos movimentos de massa.

Figura 2b: Deslizamento de terra carregando alguns blocos de pequeno diâmetro identificado na falésia.

\section{1 - Queda e tombamento de blocos}

Este tipo de movimento de massa ocorre de maneira ampla ao longo das falésias na área estudada, sendo mais comum em pontos nos quais tanto a densidade quanto a persistência das juntas tectônicas são maiores (Figura 1a e 2). Este movimento relaciona-se diretamente com a presença do primeiro domínio faciológico e suas características predominantes. Além disso, o arenito analisado encontra-se rígido, o que, segundo Lima et al., 2006, resulta de uma cimentação com sílica.

As juntas observadas são resultantes de uma tectônica pós Neógeno, o que aponta para uma atuação da neotectônica (Lima et al., 2006). Tais planos de fratura, associados a verticalidade dos taludes e ao clima quente e úmido da região influem de maneira significativa para a ocorrência de quedas e tombamentos de blocos. Tornou-se possível, desta forma, associar o alto índice pluviométrico aos movimentos de massa, já que a percolação da água, em períodos chuvosos por entre as fraturas presentes, ajuda tanto na abertura dessas juntas, quanto no deslocamento e queda de blocos rochosos. A presença das juntas em associação com a pressão exercida pela água que as preenche atuam de modo a expulsar o bloco do talude (Santos Jr. et al, 2009). Na nossa área de estudos, houve desprendimento de blocos com diâmetros variados, desde poucos centímetros a 3,5 metros os quais foram encontrados posicionados na base das falésias (Figura 1b).

\section{2 - Deslizamentos de terra}

Os deslizamentos de terra vão ocorrer associados ao segundo domínio faciológico que se apresenta mais friável e menos compactado aparecendo sobreposto aos arenitos rígidos. Nesse caso, a alternância de camadas arenosas e argilosas mais friáveis associadas às juntas, retém mais água, aumentando o peso dos sedimentos, o que facilita os deslizamentos (Figura 2b). Desta maneira, as falésias tornam-se suscetíveis a deslizamentos como consequência da perda de resistência do solo causada pelo aumento do teor de umidade do mesmo desencadeando deslizamento destes detritos.

\section{3 - Avaliação dos riscos geológicos}

Os riscos geológicos associados às falésias estudadas estão relacionados diretamente aos movimentos de massa previamente descritos. Assim, com o intuito de direcionar as informações deste trabalho para população e órgãos responsáveis, foi realizada uma avaliação dos riscos 
geológicos baseada nas características físicas e fragilidades estruturais das falésias. Esta avaliação foi feita de maneira semiquantitativa, a partir da geração do índice de riscos de acordo com as observações feitas em campo.

Assim, caracterizamos um índice preliminar dos riscos partindo da análise dos parâmetros previstos. No que diz respeito a probabilidade de ocorrência e a magnitude, devemos categorizá-los variando de 4 a 5, uma vez que pudemos constatar em inúmeros afloramentos uma maior presença de queda ou tombamento de blocos e, em menor proporção, de deslizamentos de terra. Quanto ao dano potencial a categorização varia entre reduzida e média, em razão do baixo índice de infraestruturas na área, bem como baixa incidência de residências, bens e pessoas tanto na base quanto no topo das falésias. Quanto à capacidade de resposta entre não significativa e reduzida, categorizamos a partir da vegetação presente em alguns poucos pontos do trecho, em conjunto com a ausência de sistemas de contenção, bem como de sinalização e perímetros de segurança. Temos então um índice de riscos classificado como médio.

Tabela 1. Índice de risco a partir dos valores dos parâmetros quantitativos previamente definidos.

\begin{tabular}{c|c|c|c|c|c|c|c|} 
& PO & M & D & C & Perigosidade Aparente & Vulnerabilidade & IR \\
\hline $\begin{array}{c}\text { Avaliação } \\
\text { preliminar } \\
\text { de risco }\end{array}$ & $\mathbf{5}$ & $\mathbf{4}$ & $\mathbf{3}$ & $\mathbf{1}$ & $\mathbf{2 0}$ & $\mathbf{3}$ & $\mathbf{0 . 4 8}$ \\
\hline
\end{tabular}

\section{4 - CONCLUSÃO}

Os estudos realizados na região de Trancoso à Arraial D'Ajuda permitiram a partir da observação e análise das características das falésias, recolhemos informações que exibem influência do neotectonismo a partir da existência dos planos de fratura, e da composição e disposição dos taludes. Tais conhecimentos permitiram uma análise dos riscos geológicos associados à área levando a concluir que este trecho exibe um índice de risco médio, calculado semiquantitativamente com base nos parâmetros examinados em campo. Finalmente, este trabalho serve como indicativo de alerta e abre caminho para outros estudos mais aprofundados e uma análise acerca da implementação de medidas de mitigação de risco bem como da monitoração dos mesmos a fim de evitar consequências danosas à população.

\section{6 - REFERÊNCIAS}

BRISSOS, J. et al. 2014. Avaliação do risco de instabilidade de arribas no troço costeiro SinesZambujeira do Mar. Comunicações Geológicas, Porto, Portugal, p. 883-887, jan.

FERNANDES, C.; BRISSOS, J.; SÁ CAETANO, P. 2016. Avaliação de risco associado a instabilidade de arribas em praias urbanas. In: Conferência Internacional de Riscos Urbanos, Lisboa, Portugal.

LIMA, C.C.U. 2010. Evidências da ação tectônica nos sedimentos da Formação Barreiras presentes do litoral de Sergipe e ao norte da Bahia. Revista de Geografia. Recife: UFPE - DCG/NAPA, v. especial VIII SINAGEO 1, 140-151.

LIMA, C.C.U., VILAS-BÔAS, G.S., BEZERRA, F.H.R., 2006. Faciologia e Análise Tectônica Preliminar da Formação Barreiras no Litoral Sul do Estado da Bahia. Geologia USP, Série Científica 6, 71-80.

LIMA, C. C. U; DOMINGUEZ, J.M.L., 2015. Discovery Coast: The Brazilian Landscapes First Sighted by Europeans. In: VIEIRA, B.C., SALGADO, A.A.R., SANTOS, L.J.C. Eds. Landscape and Landforms of Brazil. Cap 19. Springer: World Geomorphological Landscapes, p. 45-54.

SANTOS JR., O. F. et al. 2005. Avaliação de Processos Erosivos de Falésias em Pirangi do Norte, Parnamirim - RN. In: IV Conferência Brasileira de Estabilidade de Encostas (anais), Salvador.

SUGUIO, Kenitiro. Dicionário de geologia sedimentar e áreas afins. Rio de Janeiro, Bertrand Brasil, 1998. 